\title{
Bigarren mailako lesioen birbaskularizazioa ST segmentuaren igoera duen sindrome koronario akutuan
}

\author{
Non-culprit lesion revascularization in ST-segment elevation myocardial \\ infarction with multivessel disease
}

\author{
Nerea Mora Ayestaran ${ }^{1,}$ Felix Zubia Olaskoaga ${ }^{2}$, Ignacio Roy Añón ${ }^{3}$ \\ ${ }^{1}$ Nafarroako Ospitale Gunea, Kardiologiako zerbitzua \\ ${ }^{2}$ Donostia Unibertsitate Ospitalea, Zainketa Intentsiboen Unitatea \\ ${ }^{3}$ Nafarroako Ospitale Gunea, Kardiologiako zerbitzua \\ nerea.ayestaran@gmail.com
}

\section{Laburpena}

ST segmentuaren igoera duen sindrome koronario akutuan (STIMIA) arteria errudunaren angioplastia (AKTP) primarioa aukerako estrategia bihurtu da. Testuinguru honetan AKTP primarioa jasaten duten pazienteen \% 40-65ek arteria koronario anitzen gaixotasuna (HAG) du. Ez dago argi zer egin, pazientea hemodinamikoki egonkor egonda, arteria ez errudunekin. Entsegu kliniko berriek birbaskularizazioa osatzearen aldeko datuak agerian utzi dituzte. Berrikuspen honetan STIMIA eta HAG duten pazienteen maneiuaren inguruan dagoen ebidentzia zientifikoa laburbiltzen da.

Gako-hitzak: ST igoera duen miokardioko infartu akutua; hodi anitzeko gaixotasuna; arteria ez erruduna; interbentzio koronario perkutaneoa.

\begin{abstract}
Percutaneous coronary intervention (PCI) of the culprit lesion is now considered the gold standard in the treatment for patients with ST-segment elevation myocardial infarction (STEMI). Multivessel coronary artery disease (MVD) is found in approximately 40-65\% of patients with STEMI undergoing primary $\mathrm{PCl}$. The optimal reperfusion strategy and timing of revascularization (MV-PCl, S-PCI or IRA$P C I)$ in hemodynamically stable patients with STEMI and multivessel disease remains uncertain. Recent studies suggest that complete revascularization is superior to culprit-only revascularization in this context. In this review we summarize the available evidence on treatment options for patients with STEMI and MVD.
\end{abstract}

Keywords: ST-segment elevation myocardial infarction; multivessel disease; non-infarct related artery; percutaneous coronary intervention.

Bidalia: 2019ko abenduaren 30ean

Onartua: 2020ko martxoaren 28an

http://doi.org/10.26876/osagaiz.1.2020.292

\section{Sarrera eta helburuak}

ST segmentuaren igoera duen sindrome koronario akutuan (STIMIA), angioplastia (AKTP) primarioa arteria erruduna irekitzeko aukerako estrategia bihurtu da, betiere denbora-tarte egokiak errespetatuz eta esperientzia duen talde batek egin baldin badezake. Testuinguru horretan AKTP 
primarioa duten pazienteen \% 40-65ek arteria koronario anitzen gaixotasuna du (HAG). Paziente horiek, soilik arteria errudunaren buxadura duten pazienteekin alderatuz, hilkortasun, MIA errepikari eta birbaskularizazio-tasa handiagoak dituzte eta, azken finean, pronostiko okerragoa dute (1). Infartuarekin erlazionaturiko arteria lehenbailehen ireki beharra dago, baina oraindik ez dago argi zer egin, pazientea hemodinamikaren aldetik egonkor egonda, buxadura nabarmenak dituzten arteria ez errudunekin.

Arteria ez errudunari dagokionez, hiru estrategia nagusi daude: (a) jarrera kontserbadorea (IRA-PCI, infartuarekin erlazionaturiko arteria AKTP bitartez ireki ondoren tratamendu medikoa ezarriko da, arteria ez errudunaren birbaskularizazioa soilik sintomak daudenean edo eragite-testean iskemiaren zeinuak agertzen baldin badira eginez), (b) etapakako birbaskularizazioa (S-PCl, momentu akutuan infartuarekin erlazionatutako arteria AKTP bitartez irekiko da, arteria ez erruduna bigarren une batean irekiz) eta (c) momentu akutuko birbaskularizazio osoa (MV-PCl, epe akutuan infartuarekin erlazionaturiko arteria irekitzeaz gain, buxadura esanguratsuak dituzten arteria ez errudunak ere irekiko dira). Estrategia bakoitzak abantaila eta desabantaila teoriko batzuk ditu (1. taula, 2).

1. taula. IRA-PCI, S-PCl eta MV-PCl estrategien abantaila eta desabantaila teoriko nagusiak.

\begin{tabular}{|c|c|c|}
\hline Estrategia & Abantailak & Desabantailak \\
\hline IRA-PCI & $\begin{array}{l}\text {-Arteria erruduna soilik irekitzea, arteria ez } \\
\text { errudunak tratatzearen konplikazioak saihestuz. } \\
\text {-Prozedura laburragoa. } \\
\text {-Iskemiaren zeinuak ikusiz gero, birbaskularizazioa } \\
\text { osatzeko aukera. } \\
\text {-Pazientearekin eta familiarekin aukera } \\
\text { terapeutiko desberdinen abantaila eta } \\
\text { desabantailen inguruan eztabaidatzeko aukera. }\end{array}$ & $\begin{array}{l}\text {-Iskemia eragin dezaketen edo ezegonkorrak izan } \\
\text { daitezkeen lesioak tratatu gabe uztea. } \\
\text {-Iskemia errepikakorra ez prebenitzea. }\end{array}$ \\
\hline $\mathrm{S}-\mathrm{PCl}$ & $\begin{array}{l}\text {-Birbaskularizazio osoa. } \\
\text {-Paziente egonkortuarekin jardutea } \\
\text { (segurtasuna). } \\
\text {-Pazientearekin eta familiarekin aukera } \\
\text { terapeutiko desberdinen abantaila eta } \\
\text { desabantailen inguruan eztabaidatzeko aukera. }\end{array}$ & $\begin{array}{l}\text {-Ekonomikoak. } \\
\text {-Ospitalizazio-denbora luzeagoa (ospitaleratzean } \\
\text { zehar eginez gero). } \\
\text {-Arteria ez errudunak tratatzean konplikazioak } \\
\text { (AKTPrekin erlazionaturiko enbolizazio distala, } \\
\text { odoljarioa, albo-odoleztapena galdu eta infartu } \\
\text { gabeko eremuetan iskemia-arriskua, etab.). } \\
\text {-Lesio asintomatikoak tratatzeko arriskua (zein } \\
\text { arteria errudun tratatu zehazteke). } \\
\text {-Momentu egokiena zehazteke. } \\
\text {-Pazienteak hemodinamikako laborategira itzuli } \\
\text { beharra. }\end{array}$ \\
\hline $\mathrm{MV}-\mathrm{PCl}$ & $\begin{array}{l}\text {-Birbaskularizazio osoa. } \\
\text {-Distantziara iskemiaren tratamendua. } \\
\text {-Bigarren mailako lesio ezegonkorrak tratatu. } \\
\text {-Pazientearen erosotasuna (ez da } \\
\text { hemodinamikako laborategira itzuli behar). }\end{array}$ & $\begin{array}{l}\text {-Kontraste gehiago/ kontrastearen ondoriozko } \\
\text { nefropatiaren arriskua. } \\
\text {-Erradiazio gehiago. } \\
\text {-Prozedura luzeagoa. } \\
\text {-Arteria ez errudunak tratatzean konplikazioak } \\
\text { (AKTPrekin erlazionaturiko enbolizazio distala, } \\
\text { odoljarioa, albo-odoleztapena galdu eta infartu } \\
\text { gabeko eremuetan iskemia-arriskua, etab.). } \\
\text {-Stent-aren tronbosiaren arrisku handiagoa. } \\
\text {-Tronbosiaren eta inflamazioaren joera duen } \\
\text { ingurunean jardutea. } \\
\text {-Espasmo koronarioak arteria ez errudunen } \\
\text { larritasuna handiagotzea. }\end{array}$ \\
\hline
\end{tabular}

RA-PCl (jarrera kontserbadorea), S-PCl (etapakako birbaskularizazioa) eta $\mathrm{MV}-\mathrm{PCl}$ (momentu akutuko birbaskularizazio osoa) estrategien abantaila eta desabantaila teoriko nagusiak (taula egokitua, 2). Laburdurak: AKTP, angioplastia koronario transluminal perkutaneoa. 
Azken urteetan argitaratu diren entsegu klinikoek (PRAMI, CVLPRIT, DANAMI-3-PRIMULTI, COMPAREACUTE) eta berezik argitaratu berri den COMPLETE ikerketak buxadura nabarmenak dituzten arteria ez errudunak irekitzea onuragarria izan daitekeela iradokitzen dute. Errebisio honen helburua, STIMIA eta HAG duten pazienteen maneiuaren inguruan dagoen ebidentzia zientifikoaren bilaketa egitea da, estrategia egokiena zein den argitu nahian.

\section{Material eta metodoak}

Bilaketa Pubmed bilatzailea erabiliz egin da. Denbora eta hizkuntza mugatu gabe, eskuragarri dagoen bibliografiaren bilaketa honako hitz gakoak erabiliz egin da: "PCl" "coronary angioplasty" "revascularization" "STEMI" "ST-elevation myocardial infarction" "complete PCl" "culprit only PCI" "staged" "complete" "simultaneous" "preventive angioplasty" "non-infarct-related artery" eta "multivessel disease". IRA-PCI, MV-PCl edo/eta S-PCI alderatzen dituzten ikerketak (metaanalisiak, entsegu klinikoak, kohorteak eta erregistroak) hautatu dira. Aukeraturiko ikerketen erreferentziak aztertu dira, potentzialki interesgarriak izan daitezkeen artikulu gehigarrien bila.

Aukeraketa-irizpideak honakoak izan dira: (a) gizakietan eginiko ikerketak, (b) ikerketa mota (metaanalisiak, entsegu klinikoak, kohorteak eta erregistroak) (c) STIMIA eta hodi anitzeko gaixotasuna duten eta AKTP primarioa jasan duten pazienteak (d) IRA-PCI, MV-PCl edo/eta S-PCI alderatzen dituzten ikerketak.

Baztertze-irizpideei dagokienez, soilik talde berezien maneiua (shock kardiogenikoa, buxadura kronikoak, diabetesa, giltzurrun-gutxiegitasun kronikoa) aztertzen duten artikuluak baztertu dira.

\section{Emaitzak}

\subsection{Giden gomendioak}

Duela gutxira arte giden gomendioek bereziki emaitza kontraesankorrak zituzten eta oso heterogeneoak ziren behaketa-ikerketetan eta potentzia txikiko entsegu klinikoetan oinarritzen ziren. Gomendioak bereziki segurtasun-aldagaietan eta $\mathrm{MV}-\mathrm{PCl}$ pazienteen emaitza okerragoak agerian uzten dituzten behaketa-ikerketa eta metaanalisietan oinarritzen ziren (3).

Hala ere, azken urteetan argitaratu diren entsegu klinikoek (PRAMI, CVLPRIT, DANAMI-3-PRIMULTI, COMPARE-ACUTE) eta bereziki argitaratu berri den COMPLETE entsegu klinikoak birbaskularizazioa osatzea onuragarria eta segurua dela iradokitzen dute, pixkanaka giden gomendioak aldatuz eta gure praktika klinikoan eraginez.

Hala, momentu honetan indarrean dagoen European Society of Cardiology (ESC) gidaren arabera, alta aurretik arteria ez errudunen birbaskularizazioa egitea baloratzea gomendatzen dute (IlaA) (4). Horrek aurreko gidekiko aldaketa bat dakar, bertan ez baitzen gomendatzen arteria ez errudunaren angioplastia egitea, shock kardiogenikoan zeuden pazienteetan eta arteria erruduna ireki ondoren iskemiarekin jarraitzen zuten pazienteetan salbu (IlaB) (5).

European Society of Cardiology and the European Association for Cardio-Thoracic Surgery (ESC/EACTS) gidak antzeko gomendioa ematen du: alta aurretik arteria ez errudunen birbaskularizazioa egitea baloratu daiteke (IlaA), birbaskularizazio osoa egiteko momentu egokiena oraindik argitzeke egonik (6).

Azkenik, American College of Cardiology Foundation/American Heart Association (ACCF/AHA) gidak, iskemia miokardikoaren sintomak dituzten pazienteetan 2. denbora batean (S-PCI) arteria ez errudunaren angioplastia egitea gomendatzen du (IC) eta test ez inbasiboetan arrisku ertaina edo 
altua adierazten duten aurkikuntzak dituzten pazienteetan ere zentzuzkoa izan daitekeela dio (IlaB) (7). MV-PCIri dagokionez, gidaren eguneratze bat egon zen 2015. urtean (3): hemodinamikaren aldetik egonkor dauden pazienteetan momentu akutuan arteria ez errudunaren angioplastia errefusatzetik (IIIB), paziente jakin batzuetan MV-PCl zein S-PCl aintzat hartu daitekeela esatera (IIbB).

Testuan zehar azterturiko ikerketa desberdinen parte-hartze zein baztertze-baldintzak, definizioak, oinarrizko ezaugarriak, emaitza nagusiak eta mugak eranskineko tauletan biltzen dira.

\subsection{Soilik arteria erruduna irekitzearen aldeko datuak}

Behaketa-ikerketa ugarik arteria ez errudunetan AKTP prebentiboa egitearen arriskuak onurak baino handiagoak direla diote (prozeduran zeharreko konplikazioak, prozedura-denbora luzeagoa, kontrastearen ondoriozko nefropatia eta stent-aren tronbosia); are gehiago, maiz $\mathrm{MV}-\mathrm{PCl}$ taldeko pazienteetan emaitza okerragoak agerian uzten dituzte.

Gainera, miokardioko infartu akutuaren testuinguruan ematen den erantzun inflamatorio sistemikoaren eta hodien espasmoaren ondorioz, koronarioen odoleztapen orokorra gutxitu daiteke (8), eta, beraz, momentu akutuan esanguratsuak diruditen lesioak benetan esanguratsuak ez izatea gerta liteke.

Eskuragarri dauden behaketa-ikerketak nahiko heterogeneoak dira aztertzen dituzten aldagaiei eta jarraipenari dagokienez (eranskineko 2. taula). MV-PCI taldean Varanik (9) eta Hannanek (10) ospitale barnean, Tomak (11) 90 egunera eta Iqbalek (12) urtebetera hilkortasun altuagoa erakutsi arren, Bauerek (13) eta Cavenderek (14) hemodinamikaren aldetik egonkor dauden pazienteetan ospitale barneko hilkortasunean ez dute desberdintasunik ikusi.

Aipatu beharra dago behaketa-ikerketek, beraien izaera dela-eta, aleatorizazio-gabeziarekin erlazionaturiko alborapenak (aukeraketa-alborapena), nahaste-faktore ugari eta orekatu gabeko taldeak (paziente kopuru zein oinarrizko ezaugarriei dagokienez) izateko arrisku handia dutela. Eranskineko 3. taulan ikusi daitekeen bezala, maiz MV-PCl estrategia okerrago dauden pazienteetan egiten da eta, beraz, erregistroen emaitzak kontu handiz aztertu behar ditugu. Hori kontuan izanik, Jaguszewskik (15) STIMIA eta HAG duten "Swis AMIS Plus" erregistroko pazienteak $(n=4,941)$ beren arriskuaren arabera estratifikatu dituzte, IRA-PCI $(n=3,833)$ eta MV-PCI $(n=1,108)$ estrategietan ospitale barneko hilkortasuna eta GZKKNak (gertakari zerebrobaskular eta kardiako kaltegarri nagusiak) aztertuz. MV-PCI taldean ospitale barneko hilkortasuna altuagoa izan da (OR:1,80; KT\%95:1,37-2,38; $p<0,001$ ), baina pazienteak arriskuaren arabera estratifikatu ondoren, ez dirudi MV-PClk ospitale barneko hilkortasun altuagoa dakarrenik. Are gehiago, MV-PCl estrategiaren erabilera ez da ospitale barneko hilkortasunaren iragarle gisa identifikatu.

\subsection{Estrategien artean ez da desberdintasunik ikusi}

Shock kardiogenikoan dauden pazienteak barne hartzen dituzten Santos (16) eta Jaguszewskik (15) eginiko behaketa-ikerketetan, ospitale barneko hilkortasunari dagokionez ez da desberdintasunik ikusi. Modu berean, Bauer (13) eta Cavenderek (14) beste aldagai batzuetan birbaskularizazioa osatzearen aurkako datuak aurkeztu arren, hemodinamikaren aldetik egonkor dauden pazienteetan ez dute hilkortasunaren handitzerik ikusi. Datu hauek ez datoz bat Varanik (9) adierazitakoarekin, shock kardiogenikoan dauden pazienteak barne harturik MV-PCIn ospitale barneko hilkortasun altuagoa erakutsi baitu. 
Behaketa-ikerketa hauek ez ezik, hiru entsegu klinikok ere ez dute estrategien arteko desberdintasunik erakutsi. 2004. urteko HELP-AMI entsegu klinikoak ( $n=69), 12$ hilabetetan zehar birbaskularizazioa errepikatzeko beharra eta bigarren aldagai gisa GKKN (hilkortasuna, MIA errepikaria eta larrialdiko birbaskularizazio-beharra) aztertu ondoren, ez du desberdintasunik erakutsi IRA-PCI $(n=17)$ eta MV-PCI $(n=52)$ estrategien artean, \% 35 vs $\% 17(p=0,247)$ eta \% 3,8 vs $\% 0(p=0,164)$, hurrenez hurren (17). Hala ere, potentzia txikiko ikerketa baten aurrean gaude, taldeak ez daude ondo orekatuta paziente kopuruari dagokionez eta gainera argi dago garai horretan eskuragarri zegoen tratamendu medikoa eta stent motak eta gaur egun dauden baliabideak ez direla berdinak.

Beste alde batetik, birbaskularizazio-estrategia desberdinek ezker bentrikuluaren funtzioan izan dezaketen eragina aztertzen da, ezkerreko bentrikuluaren disfuntzioa epe motz zein luzeko konplikazioen eta hilkortasunaren iragarle garrantzitsua baita (18). Hori kontuan izanik, Dambrinkek $(n=121)$ IRA-PCI $(n=41)$ eta S-PCI ( $n=80,<3$ aste) estrategiek eiekzio-frakzioan duten eragina aztertu dute. 6 hilabeteko jarraipenaren ondoren, ez da desberdintasun esanguratsurik aurkitu IRA-PCI $(\% 56,9 \pm 9,3)$ eta S-PCI $(\% 58,9 \pm 9,4)$ estrategien artean, $\mathrm{p}=0,362$ izanik (19).

2015. urtean argitaratu zen PRAGUE-13 entsegu kliniko irekian ere $(n=214)$, ez da desberdintasunik ikusi IRA-PCI ( $n=108)$ eta S-PCI ( $n=106,3-40$ egun) estrategien artean. 38 hilabeteko jarraipenaren ondoren, GKKN aldagai konposatua (hilkortasuna, MIA errepikaria eta istripu zerebrobaskularra) IRA$\mathrm{PCl}$ taldeko pazienteen \% 13,9an eta S-PCI taldeko \% 16,0an gertatu da (HR:1,35; KT\%95:0,66- 2,74; $p=0,407)$. Aldagai nagusiaren banakako osagaietan eta arteria ez errudunaren birbaskularizazioan (HR:0,51; KT\%95:0,24-1,11; $p=0,089$ ) ere ez da desberdintasun estatistikoki esanguratsurik ikusi (20).

\subsection{Birbaskularizazioa osatzearen aldeko datuak}

Hodi anitzeko gaixotasuna gaixotasun koronario aurreratu baten isla da eta ateroesklerosi zehaztugabe honek plaken ezegonkortasuna, karga iskemiko handia eta infarturik gabeko zonetan uzkurgarritasun desegokia eragin dezakeela dirudi (21). Birbaskularizazioa osatzea, arteria ez errudunak irekiz pazienteen karga iskemikoa gutxitu eta biziraupena hobetuko delako hipotesian oinarritzen da.

Jeger (8) eta Manarik (22) eginiko behaketa-ikerketek ez ezik, orain arte egin diren entsegu kliniko gehienek ere birbaskularizazioa osatzearen aldeko datuak erakutsi dituzte.

Politik ( $n=214)$ IRA-PCI ( $n=84)$, S-PCI ( $n=65,56,8 \pm 12,9$ egun) eta MV-PCI $(n=65)$ estrategiak alderatu ditu, 30 hilabetetan zehar GKKNak aztertuz (hilkortasuna, ospitale barneko hilkortasuna, MIA errepikaria, sindrome koronario akutuagatik ospitaleratu beharra eta birbaskularizazioa errepikatu beharra). IRA-PCl estrategiarekin alderatuz, MV-PCI (HR:0,495; KT\%95:0,262-0,933, p=0,030) zein SPCI (HR:0,377; KT\%95:0,194-0,732, p=0,004) estrategiek GKKN izateko arrisku gutxiago erakutsi dute. GKKNen gutxitze hau, ospitale barneko hilkortasuna $(p=0,037)$, berriro ospitaleratzea $(p<0,001)$ eta birbaskularizazioa errepikatu beharra $(p<0,001)$ gutxitzearen bitartez gertatu da. Izan ere, MIA errepikarian eta hilkortasunean ez da desberdintasun esanguratsurik aurkitu. Kaplan-Meier grafikoan ikusten denez (1. irudia), birbaskularizazio osoko taldeetan GKKN zein AKTP gabeko biziraupenak handiagoak izan dira, S-PCl eta MV-PCl taldeen artean desberdintasunik ikusi gabe $(p=0,815$ eta $p=0,467$, hurrenez hurren) (23). 

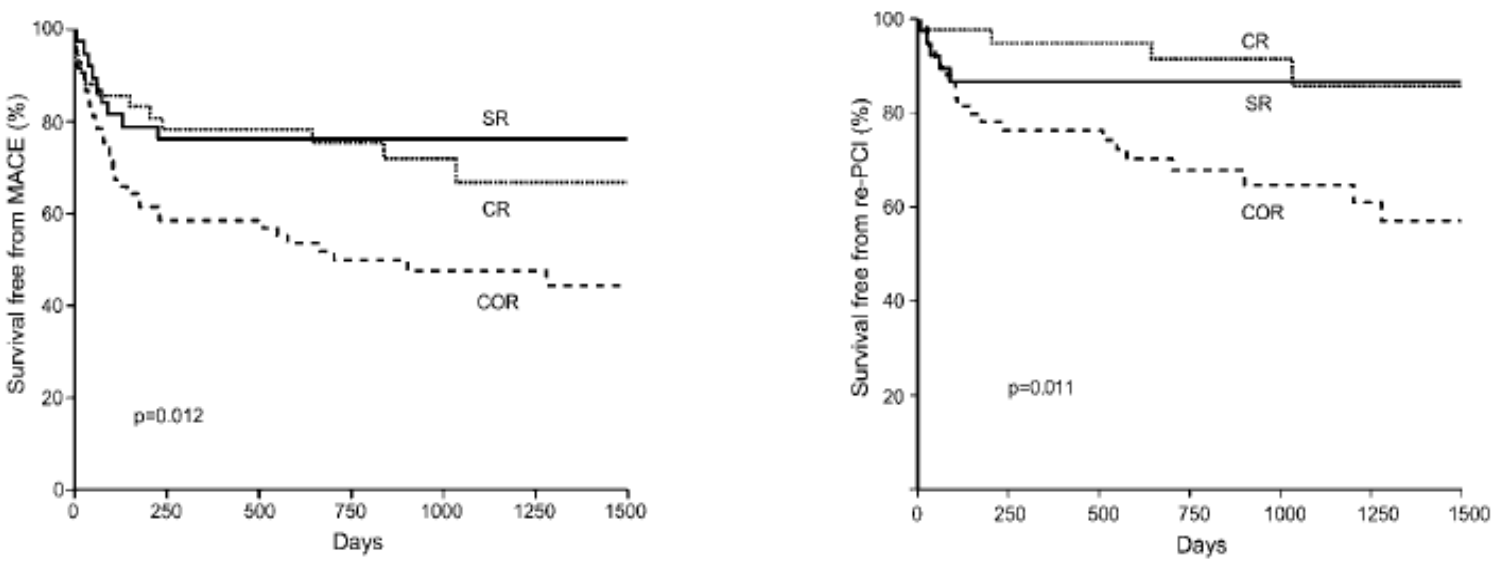

\begin{tabular}{|c|c|c|c|c|c|c|c|c|c|c|c|c|c|c|}
\hline Pts at risk COR & 84 & 47 & 40 & 25 & 17 & 15 & 8 & Pts at risk COR & 84 & 50 & 41 & 26 & 17 & 16 \\
\hline SR & 65 & 53 & 45 & 20 & 9 & 3 & 0 & SR & 65 & 55 & 47 & 22 & 9 & 3 \\
\hline CR & 65 & 53 & 49 & 28 & 15 & 6 & 3 & CR & 65 & 56 & 52 & 29 & 17 & 7 \\
\hline
\end{tabular}

1. irudia. Politik buruturiko entsegu klinikoko hiru estrategien GKKN gabeko eta AKTP gabeko biziraupenen Kaplan-Meier grafikoak. Hiru estrategien GKKN gabeko biziraupena (ezkerreko grafikoa) eta AKTP gabeko biziraupena (eskuineko grafikoa) ageri dira. Lerro jarraituak S-PCIri (irudian SR), punteatuak MV-PClri (irudian $\mathrm{CR}$ ) eta trazudunak IRA-PCIri (irudian COR) egiten diete erreferentzia. Laburdurak: AKTP (irudian PCI), angioplastia koronario transluminal perkutaneoa; GKKN (irudian MACE), gertakari kardiako kaltegarri nagusiak.

Ikerketaren mugei dagokienez, taldeak ez daude ondo orekatuta paziente kopuruari dagokionez, eta $\mathrm{S}-\mathrm{PCl}$ taldean hiru hodiren gaixotasuna duten paziente gehiago daude.

PRAMI (Preventive Angioplasty in Acute Myocardial Infarction) entsegu kliniko irekian ( $n=465)$, IRA$\mathrm{PCl}(n=234)$ eta MV-PCI $(n=231)$ estrategiak alderatu dituzte. 23 hilabetetan zehar GKKNak aztertu ondoren (bihotz-hilkortasuna, MIA errepikaria eta angina errefraktarioa), angioplastia prebentiboak GKKN modu esanguratsu batean murriztu du (HR:0,35; KT\%95:0,21-0,58; $\mathrm{p}<0,001)$, murrizketa hori lehenengo 6 hilabeteetan dagoeneko agerikoa izanik eta jarraipenean zehar mantenduz (2. irudia). Aldagai nagusiaren osagaiei dagokienez, MIA errepikaria (HR:0,32; KT\%95:0,13-0,75; $p=0,009$ ) eta angina errefraktarioa (HR:0,35; KT\%95:0,18-0,69; $p=0,002$ ) modu esanguratsuan murriztu dira, baina arrazoi kardiakoen ondoriozko heriotza-kasu gutxiago egon badira ere, ez dira modu esanguratsuan murriztu (HR:0,34; KT\%95:0,11-1,08; $\mathrm{p}=0,07$ ). Modu berean, MV-PCI jasan duten pazienteek birbaskularizazio-behar gutxiago izan dute (HR: 0,30; KT\%95:0,17-0,56; $p \leq 0,001$, bigarren mailako aldagaia) (24). 


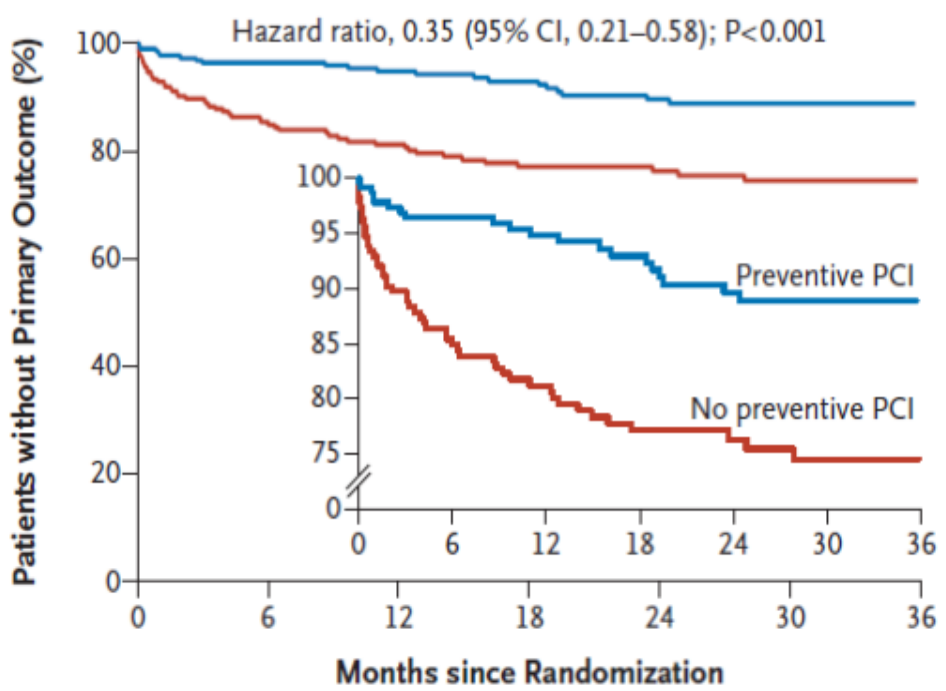

$\begin{array}{lrrrrrrr}\text { No. at Risk } & & & & & & & \\ \text { Preventive PCI } & 234 & 196 & 166 & 146 & 118 & 89 & 67 \\ \text { No preventive PCl } & 231 & 168 & 144 & 122 & 96 & 74 & 50\end{array}$

2. irudia. PRAMI entsegu klinikoko aldagai nagusiaren Kaplan-Meier grafikoa. Aldagai nagusia (GKKN) bihotzeko arrazoien ondoriozko hilkortasunaren, MIA errepikariaren eta angina errefraktarioaren batura da. Barneko grafikoak emaitza berdinak adierazten ditu, baina eskala handiagoan. "Preventive PCl"k MV-PCIri egiten dio erreferentzia eta "No preventive PCI"-k IRA-PCIri. Laburdurak: GKKN, bihotz-gertakari kaltegarri nagusiak; MIA, miokardioko infartu akutua.

Ikerketaren mugei dagokienez, ikerketaren ikuspuntu dikotomikoa aipatu beharra dago ( $\geq \% 50$ buxadura birbaskularizatzeko hautagarri kontsideratu dute, estenosi larriak eta ez hain larriak talde berean sartuz eta ebaluazio morfologiko zein funtzionalik egin gabe). Ikerketa 600 paziente biltzeko diseinatuta zegoen, baina aldagai nagusian birbaskularizazio osoaren aldeko desberdintasun esanguratsuak topatu zirenez, goiz geldiarazi zuten. Hori kontuan izanik, emaitza hauek kontu handiz aztertu behar ditugu, entsegu klinikoa goiz eteteak tratamenduaren eragina gainestimatzea eragin baitezake, bereziki laginaren tamaina txikia eta aztertzen ari den gertaera beste banakako gertakarien elkarketa izanik.

CVLPRIT (Complete Versus Culprit-Lesion Only Primary PCI) entsegu kliniko irekian ( $n=296)$, IRA-PCI $(n=146)$ eta birbaskularizazio osoa alderatu dira (MV- PCI [n=96] eta alta aurretik eginiko S-PCI [n=54] bereizi gabe). 12 hilabetetan zehar GKKN aztertu ondoren (hilkortasuna, MIA errepikaria, BG eta birbaskularizazioa errepikatu beharra), birbaskularizazio osoa jasan duten pazienteetan GKKN modu esanguratsuan txikiagoa izan da (HR: 0,45; KT\%95: 0,24-0,84; $p=0,009$, 3. Irudia). Aldagai nagusiaren osagaietan ere kasu gutxiago egon arren, emaitzak ez dira estatistikaren aldetik esanguratsuak izan: hilkortasuna (HR: 0,38; KT\%95: 0,12-1,20; $p=0,09$ ), MIA (HR: 0,47; KT \%95: 0,09-2,59; $p=0,38$ ), BG (HR: 0,47; KT \%95: 0,16-1,38; $p=0,16$ ) eta birbaskularizazioa errepikatu beharra (HR: 0,46; KT \%95: $0,20-1,08 ; p=0,07)(25,26)$. Ikerketa horren epe luzeagoko emaitzak argitaratu berri dira (27). Bertan, batez beste 5.6 urteko jarraipenaren ondoren GKKN gutxiago eman dira birbaskularizazio osoko taldean (\% 24,0 vs \% 37,7, HR: 0,57; KT\%95: 0,37-0,87; $p=0,0079$ ). 


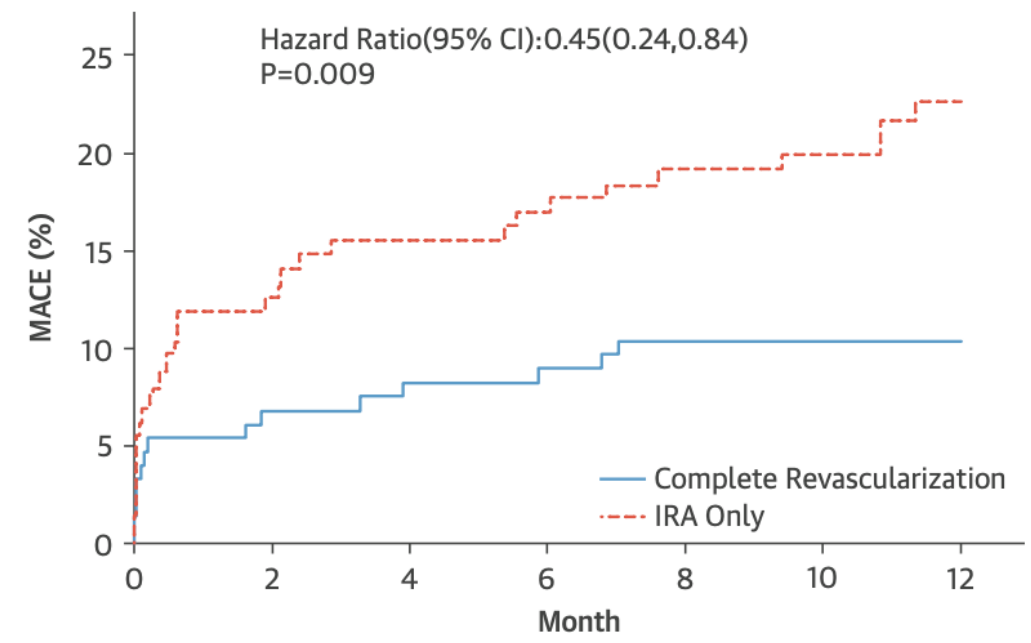

Number at risk:

$\begin{array}{ccccccc}\text { Complete:150 } & 131 & 129 & 128 & 125 & 108 & 73 \\ \text { IRA Only:146 } & 122 & 118 & 116 & 111 & 98 & 68\end{array}$

3. irudia. CVLPRIT entsegu klinikoko aldagai nagusiaren Kaplan-Meier grafikoa. Aldagai nagusia (GKKN, irudian MACE) edozein arrazoiren ondoriozko hilkortasunaren, MIA errepikariaren, BG eta birbaskularizazioa errepikatu beharraren batura da. "Complete PCl"-k MV-PCIri eta ospitalizazioan zehar eginiko S-PCIri egiten dio erreferentzia eta "IRA Only PCI"-k IRA-PCIri. Laburdurak: GKKN, gertakari kardiako kaltegarri nagusiak; MIA, miokardioko infartu akutua; BG, bihotz-gutxiegitasuna.

Ikerketaren mugei dagokienez, entsegu klinikoa ez dago diseinatuta aldagai nagusiaren osagaien arteko desberdintasunak ikusteko (potentzia estatistiko baxua) ez eta MV-PCl eta ospitalizazioan zehar eginiko S-PCI alderatzeko ere. Ikerketan birbaskularizazio osoko bi estrategiak alderatu arren (MV-PCl taldean GKKN gutxiago ikusiz), datu hauetatik ezin da ondorio sendorik atera, azpitalde hauetan laginaren tamaina txikia eta talde batean edo bestean sartzea ez baita ausazkoa izan (erabakia medikuek hartu dute, zergati klinikoetan oinarrituz). Modu berean, ezin da aukeraketaalborapena erabat baztertu, aleatorizazioa angiografiaren emaitzak izan ondoren egin baita. Pazienteen oinarrizko ezaugarriei dagokienez, IRA-PCI taldean tronboen aspiraziorako kateterra gehiago erabili da $(p=0,047)$. Desberdintasuna estatistikaren aldetik esanguratsua izan arren, ez dirudi klinikoki aintzakotzat hartzeko modukoa izan daitekeenik edo estrategien alderaketan eragin handia izan dezakeenik. Izan ere, gaiaren inguruko ebidentzia berriak tronboen aspiraziorako kateterraren erabileraren abantailak zalantzan jartzen ditu (7).

DANAMI 3-PRIMULTI entsegu kliniko irekian ( $n=627)$ IRA-PCI $(n=313)$ eta alta aurretik eginiko S-PCI $(n=314$, 2. egunetik aurrera, betiere alta aurretik) alderatu dira. 12 hilabetetan zehar GKKN aztertu ondoren (hilkortasuna, MIA errepikaria eta birbaskularizazioa errepikatu beharra), S-PCI taldean esanguratsuki baxuagoa izan da (HR:0,56; KT\%95:0,38-0,83; $p=0,004$ ). Gutxitze hori birbaskularizaziobeharra gutxitzearen bitartez eman da (HR:0,31; KT\%95:0,18- 0,53; $\mathrm{p}<0,0001$ ), hilkortasunean (HR:1,40; KT\%95:0,63-3,00; $p=0,43$ ) eta MIAn (HR:0,94; KT\%95:0,47-1,90; $p=0,87$ ) ez baita desberdintasun esanguratsurik topatu (4. irudia) (28). 

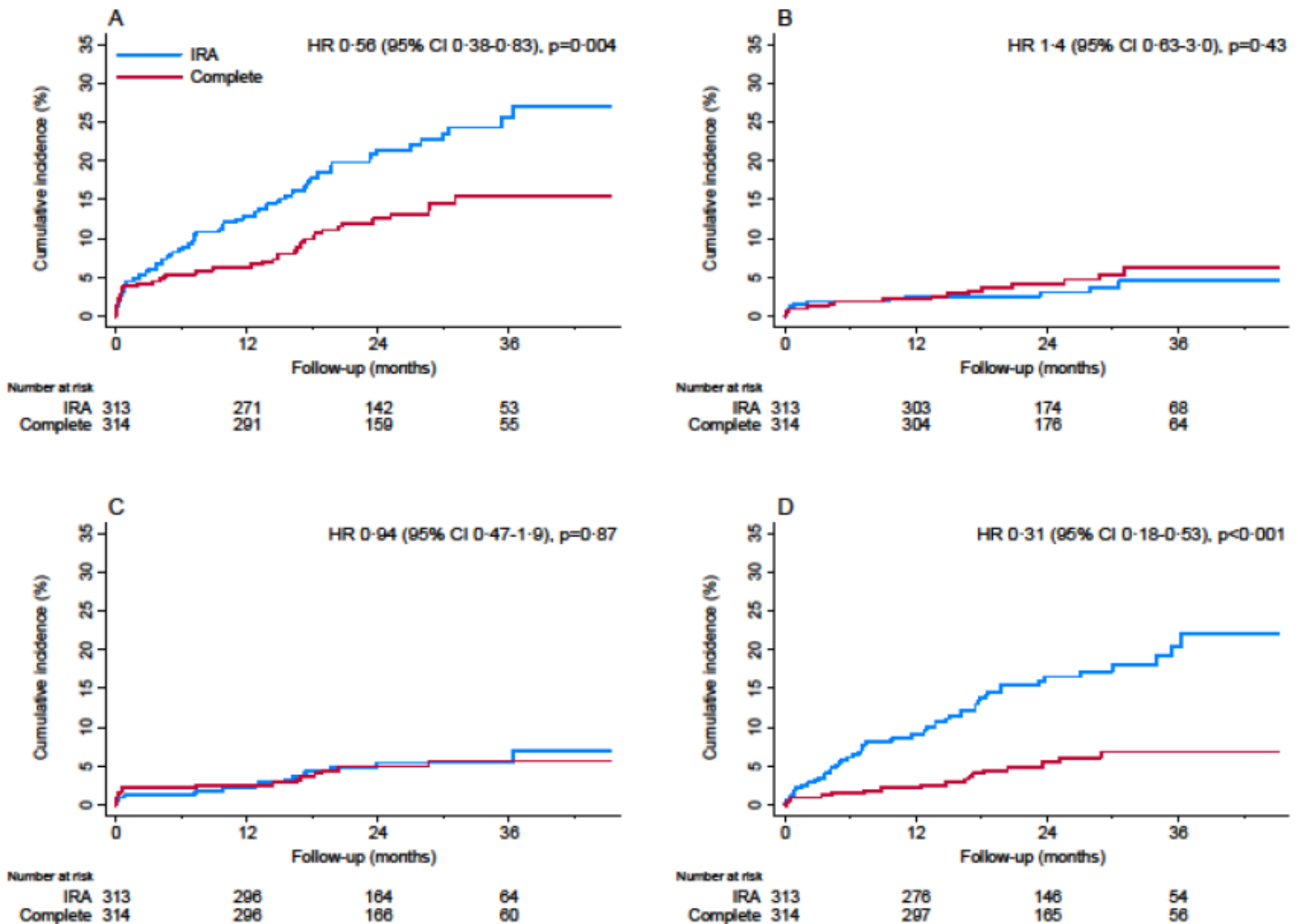

4. irudia. DANAMI 3-PRIMULTI entsegu klinikoko aldagai nagusiaren (A), hilkortasunaren (B), MIAren (C) eta birbaskularizazioa errepikatu beharraren (D) Kaplan-Meier grafikoak. Aldagai nagusia (GKKN) edozein arrazoiren ondoriozko hilkortasunaren, MIA errepikariaren eta iskemiaren ondorioz birbaskularizazioa errepikatu beharraren batura da. "Complete"-k S-PClri eta "IRA"-k IRA-PCIri egiten diete erreferentzia. Laburdurak: GKKN, bihotzeko gertakari kaltegarri nagusiak; MIA, miokardioko infartu akutua; HR, hazard ratio.

Ikerketaren mugei dagokienez, ikerketa DANAMI-3 entsegu-programaren parte denez, pazienteak aurretik stent-aren ezarpen atzeratua (DANAMI-3-DEFER) eta postkondizionamendu iskemikoa (DANAMI-3-POSTCON) aztertzeko aleatorizatuak izan dira, cox erregresioan interakziorik ikusi gabe. Bestalde, FFR (fractional flow reserve) soilik ikerketaren adar batean erabili denez, taldeen arteko alderagarritasuna ezin da bermatu. Izan ere, S-PCl adarrera aleatorizatutako pazienteen $\% 31 \mathrm{n}$ ez da birbaskularizazioa osatu, buxadura hemodinamikaren aldetik esanguratsua ez izateagatik. Modu berean, prozedura STIMIAren errekuperazio-fasean zehar egin da (2. egunetik aurrera, miokardioa oraindik egonkortu gabe egonik) eta horrek FFRaren balioaren fidagarritasunean eragina izan dezake.

DANAMI-3-PRIMULTI entseguaz gain, beste bi entsegu klinikotan ere birbaskularizazioa FFR bidez gidatu da. COMPARE-ACUTE entsegu klinikoan $(n=885)$, IRA-PCI $(n=590)$ eta FFRak gidaturiko birbaskularizazio osoa alderatu dira $(\mathrm{n}=295)$. Birbaskularizazio osoa kasu gehienetan prozedura berdinean egin da (MV-PCl), baina kasu batzuetan medikuaren irizpidearen arabera (lesio konplexuak, arazo logistikoak...) birbaskularizazioa bigarren denbora batean osatu da (S-PCI), betiere alta aurretik eta ahal izanez gero lehenengo 72 orduetan burutuz. 12 hilabetetan zehar GKKN aztertu ondoren (edozein arrazoiren ondoriozko hilkortasuna, MIA, birbaskularizazioa eta istripu zerebrobaskularra), birbaskularizazio osoa jasan duten pazienteetan GKKN modu esanguratsuan txikiagoa izan da (HR: 0,35; KT\%95: 0,22-0,55; $p<0,001$, 5. irudia). Hala ere, aldaketa hori bereziki birbaskularizazioa errepikatu behar izanak gidatu du (HR:0,32; KT\%95: 0,20-0,54; p<0,001), hilkortasuna eta MIA bezalako aldagai gogorretan desberdintasunik aurkitu gabe (29). 


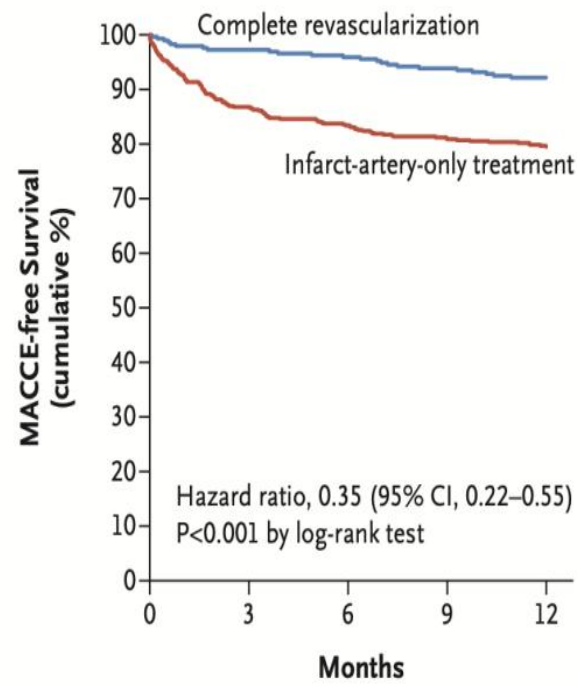

\begin{tabular}{|c|c|c|c|c|c|}
\hline No. at Risk & & & & & \\
\hline $\begin{array}{l}\text { Complete } \\
\quad \text { revascularizatio }\end{array}$ & 295 & 286 & 281 & 264 & 215 \\
\hline Infarct artery & 590 & 512 & 492 & 457 & 371 \\
\hline
\end{tabular}

5. irudia. COMPARE-ACUTE entsegu klinikoko aldagai nagusiaren Kaplan-Meier grafikoa.

Aldagai nagusia (GKKN, irudian MACCE) edozein arrazoiren ondoriozko hilkortasunaren, MIAren, birbaskularizazioaren eta istripu zerebrobaskularraren batura da. Laburdurak: GKKN, gertakari kardiako kaltegarri nagusiak; MIA, miokardioko infartu akutua; HR, hazard ratioa.

DANAMI-3-PRIMULTI entsegu klinikoan gertatu zen bezalaxe, entsegu kliniko honetan ere angiografiaren aldetik esanguratsuak ziruditen arteria ez errudunen erdiak ez dira funtzionalki esanguratsuak izan (FFR >0,80). Aipatu dugunez kontuan eduki behar da FFRa STIMIAren fase akutuan egin dela eta bertan mikrozirkulazioan gertatzen diren aldaketa hemodinamikoek emaitzen fidagarritasunean eragina izan dezaketela. Modu berean, entsegu klinikoa ireki denez, pazienteak zein medikuak koronariografiaren emaitza jakiteak jarraipenean zehar birbaskularizazio-prozedura gehiago eskatzea eragin dezake, hau izanik, hain zuzen ere, $\mathrm{MV}-\mathrm{PCl}$ prozeduraren aldeko emaitza nagusia.

Azkenik, 2019. urtearen amaieran COMPLETE entsegu klinikoa argitaratu berri da, egun argitaratuta dauden entsegu klinikoen artean potentzia estatistiko handiena duena. Entsegu kliniko horretan IRA$\mathrm{PCl}(n=2025)$ eta S-PCI $(n=2016)$ estrategiak alderatu dira. Jarraipenean zehar, bi ko-aldagai nagusiak (1 arrazoi kardiobaskularren ondoriozko hilkortasuna eta MIA aldagai konposatua; 2 hilkortasun kardiobaskularra, MIA edo iskemiak gidaturiko birbaskularizazioa) baxuagoak izan dira birbaskularizazio osoa jaso duten pazienteetan (HR: 0,74; KT\%95: 0,60-0,91; p=0,004; HR: 0,51; KT\%95: 0,43-0,61; $p<0,001$, hurrenez hurren, 6. irudia). Hala ere, desberdintasun hori MIA errepikarien gutxitzeak gidatu du, bereziki ST segmentuaren igoera ez duen MIAen gutxitzeak (\% 3,27 vs 5,19$)$, hilkortasun kardiobaskularrean desberdintasunik aurkitu gabe $(30)$. 
A First Coprimary Outcome

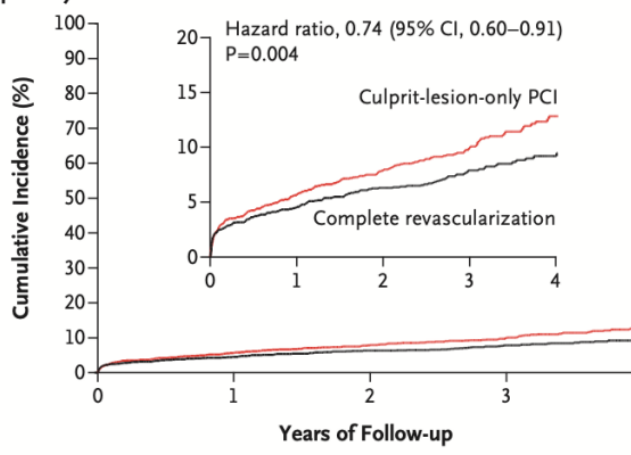

\begin{tabular}{|c|c|c|c|c|}
\hline No. at Risk & & & & \\
\hline $\begin{array}{l}\text { Culprit-lesion- } \\
\text { only PCI }\end{array}$ & 2025 & 1897 & 1666 & 933 \\
\hline $\begin{array}{l}\text { Complete revas- } \\
\text { cularization }\end{array}$ & 2016 & 1904 & 1677 & 938 \\
\hline
\end{tabular}

B Second Coprimary Outcome

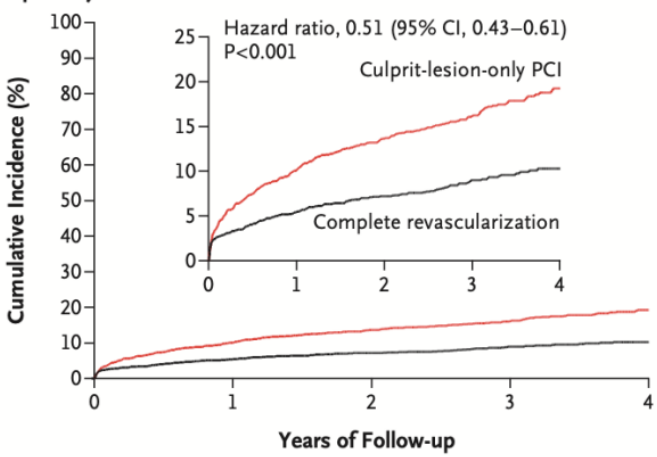

\begin{tabular}{l} 
No. at Risk \\
$\begin{array}{c}\text { Culprit-lesion- } \\
\text { only PCl } \\
\text { Complete revas- } \\
\text { cularization }\end{array}$ \\
\hline
\end{tabular}
1559

1659
294

329

6. irudia. COMPLETE entsegu klinikoko lehenengo eta bigarren ko-aldagai nagusien KaplanMeier grafikoak. Lehenengo ko-aldagai nagusia (A) arrazoi kardiobaskularren ondoriozko hilkortasunaren eta MIA aldagaien batura da, eta bigarren ko-aldagaiak (B) MIA, hilkortasun kardiobaskularra eta iskemiak gidaturiko birbaskularizazioa batzen ditu.

\subsection{Birbaskularizazioa osatuz gero, zein da estrategiarik egokiena?}

Etapakako birbaskularizazioa (S-PCI) aurreko bi estrategien (IRA-PCI eta MV-PCI) bitarteko estrategia bat da. Birbaskularizazioa osatzearen bitartez pazientearen karga iskemikoa gutxitzea eta horrela biziraupena hobetzea bilatzen du, MV-PCl estrategiaren desabantaila batzuk saihestuz. Paziente egonkortuarekin jarduten duzu, baina pazienteek hemodinamikako laborategira itzuli behar dute (bigarren prozedura batek eragin ditzakeen konplikazioak bere gain hartuz) eta horrek ospitalizaziodenbora eta gastu ekonomikoak handitzen ditu. Birbaskularizazioa osatzeko estrategiarik egokiena zein den zehaztea ez da erraza, galdera horri erantzuna emateko dugun ebidentzia oso urria baita. Izan ere, birbaskularizazio osoko $\mathrm{MV}-\mathrm{PCl}$ eta $\mathrm{S}-\mathrm{PCl}$ estrategiak alderatzen dituzten ikerketa gutxi izateaz gain, potentzia estatistiko txikikoak dira, oso heterogeneoak aldagaiei eta jarraipenari dagokienez eta, gainera, etapakako birbaskularizazioa egiteko momenturik egokiena argitzeke dagoenez, S-PCl estrategiaren barnean aniztasun handia dago.

Kornowskik (31) aztertutako kohortean MV-PCl estrategia hilkortasunarekin, stent-aren tronbosiarekin eta odoljario handiagoarekin erlazionatuta dagoela ikusi da. Kornowskik ez ezik, Varanik (9) eta Manarik (22) eginiko behaketa-ikerketek ere MV-PCl estrategiaren aurkako datuak agerian utzi dituzte. Bi ikerketetan MV-PCI taldeko pazienteek 30 egunera hilkortasun altuagoa izan dute, baina Varanik laginetik Killip III eta IV duten pazienteak kendu ondoren eta Manarik 2 urteko jarraipenean zehar desberdintasun hauek desagertu egin dira. Gainera, pazienteen oinarrizko ezaugarriak oso desberdinak dira, MV-PCI taldean arriskuko ezaugarri gehiago agertuz.

Hala ere, datu hauek ez datoz bat S-PCl eta MV-PCl estrategiak alderatzen dituzten entsegu klinikoek diotenarekin.

2004. urtean Ochalak ( $n=92$ ) birbaskularizazio osoko bi estrategiek ezkerreko bentrikuluaren eiekziofrakzioaren berreskurapenean duten eragina aztertu zuten eta MV-PCl taldean eiekzio-frakzioaren hobekuntza azkarragoa eta handiagoa ikusi zuten. Bigarren aldagai gisa GKKNak ere aztertu dituzte (hilkortasuna, MIA errepikaria eta birbaskularizazioa errepikatu beharra), eta bi estrategien artean desberdintasunik ez zuten ikusi (18).

Hala ere, argi dago garai horretan eskuragarri zeuden baliabideak eta gaur egungoak ez direla berdinak. Hau kontuan izanik, Tarasovek $(n=89)$ bigarren belaunaldiko stent farmakoaktiboek 
(Zotarolimus) birbaskularizazio osoan dituzten emaitzak aztertu dituzte, $\mathrm{MV}-\mathrm{PCl}(\mathrm{n}=46)$ eta S-PCI ( $n=43,8,5 \pm 4,2$ egun) estrategiak alderatuz. 6 hilabetetan zehar GKKNak aztertu ondoren (hilkortasuna, MIA errepikaria eta birbaskularizazioa errepikatu beharra), behin-behineko emaitzek ez dute desberdintasun esanguratsurik erakutsi bi estrategien artean (32).

Modu berean, Maamounek ( $n=78)$ S-PCI ( $n=36,<7$ egun) eta MV-PCI ( $n=42)$ estrategiak alderatu dituzte. 12 hilabetetan zehar GKKNak aztertu dituzte (hilkortasuna, MIA errepikaria, angina errepikariagatik ospitaleratu beharra, birbaskularizazioa errepikatu beharra eta istripu zerebrobaskularra), bi taldeen artean desberdintasun estatistikoki esanguratsurik topatu gabe (33).

Ochala, Tarasov eta Maamounek eginiko entsegu klinikoek ez ezik, Politik ere ez du desberdintasunik erakutsi bi estrategien artean GKKNei dagokienez. Hala ere, ikerketa guztiek duten potentzia estatistiko txikia muga garrantzitsu bat da eta ezin da ondorio sendorik atera.

\section{Eztabaida}

\subsection{Birbaskularizazio osoa segurua da?}

Argitaratuta dauden entsegu kliniko nagusiek (Politi, PRAMI, DANAMI-3-PRIMULTI, PRAGUE-13, COMPARE-ACUTE eta COMPLETE) birbaskularizazioa osatzea segurua dela iradokitzen dute. Izan ere, birbaskularizazio osoko taldean prozeduraren iraupena, erradiazio-dosia eta kontraste kopurua handiagoak izan diren arren, ez dute istripu zerebrobaskularren, odoljario nagusien eta kontrastearen ondoriozko nefropatien handitze esanguratsurik ikusi. CVLPRIT entsegu klinikoan ere ez da kontrako ondorioen handitzerik ikusi, baina giltzurrun-gutxiegitasun larria duten pazienteak ikerketatik kanpo geratu dira eta birbaskularizazio osoa jasan duten pazienteen \% 36an, zehazten ez diren arrazoi klinikoak direla-eta, $\mathrm{MV}-\mathrm{PCl}$ egin beharrean S-PCl egin da.

Bestalde, arteria ez errudunean AKTP egiteak potentzialki prozedura inguruko MIA iatrogenikoa eragin dezake eta horrek aipamen berezia merezi du. PRAMI (\% 100) eta CvIPRIT (\% 64) entsegu klinikoetan birbaskularizazio osoa momentu akutuan (MV-PCI) egin denez, ezin izan dira prozedura inguruko MIAk identifikatu. Izan ere, TnTak 12-24 ordura lortzen du bere gorengo maila eta 10-14 egun behar ditu normaltasunera itzultzeko; beraz, STIMIAren testuinguruan ematen den troponinen igoerak prozeduran zehar gertaturiko MIA txikiak estaltzen ditu. Gainera, CVLPRIT entsegu klinikoan MIArako erabilitako definizioa zorrotza izan da eta AKTP ondorengo troponinen igoerari ez zaio errutinaz begiratu. PRAGUE-13 entsegu klinikoan, etapakako birbaskularizazioa beranduago egin da (3-40 egunera) eta pazienteen \% 3,8an prozedura inguruko MIA iatrogenikoak identifikatu dituzte, horiek pronostiko onekoak izan diren arren.

Hau kontuan izanik, CVLPRIT entsegu klinikoaren azpi-ikerketa bat egin da, birbaskularizazio osoak, arteria ez errudunetan prozedura inguruko MIA eraginez, infartuaren tamainaren handitzea dakarren aztertu nahian. IRA-PCl estrategiarekin alderatuz, birbaskularizazio osoko taldean alta aurretik eginiko erresonantzia kardiakoan arteria ez errudunetan MIA gehiago antzeman dira, baina jarraipenean zehar eginiko erresonantzian ez da infartuaren tamainan handitzerik ikusi (34).

\subsection{Birbaskularizazio osoa eraginkorra da?}

Birbaskularizazio osoa egitea segurua dela dirudi, baina orain arte ez zegoen hain argi pazientearengan tratamendu mediko egoki batekin lortu ezin diren onurak lortzen ziren, onura horiek epe luzera mantentzen ziren eta honek guztiak pazientearen pronostikoan hobekuntza bat zekarren.

Behaketa-ikerketa ugarik $\mathrm{MV}-\mathrm{PCl}$ taldean emaitza okerragoak agerian utzi dituzte, baina arrisku altuko pazienteetan $\mathrm{MV}-\mathrm{PCl}$ estrategia gehiago erabiltzen da (14). Horrek, behaketa-ikerketen muga handi bat agerian jartzen du: $\mathrm{MV}-\mathrm{PCI}, \mathrm{S}-\mathrm{PCl}$ edo IRA-PCI aukeraketa irizpide klinikoen arabera egiten da eta maiz, birbaskularizazio osoa pairatzen duten pazienteek egoera kliniko okerragoa dute. Aukeraketa-alborapena leundu nahian, ezegonkortasun hemodinamikoa bezalako egoera klinikoak 
identifikatu eta estratifikazioa egin daiteke, baina beste faktore asko ez dira hain errazak identifikatzen eta sailkatzen. Beraz, emaitza hauek kontu handiz interpretatu behar dira, MV-PCI estrategiaren emaitza okerragoak pazienteen egoera kliniko okerragoaren ondoriozkoak izan baitaitezke.

Azkeneko entsegu klinikoek birbaskularizazioa osatzearen aldeko abantailak erakutsi dituzte, baina abantaila horiek, argitaratu berri den COMPLETE entsegu klinikoan salbu, birbaskularizazioa errepikatzearen beharra gutxitzeagatik gertatu dira, hilkortasuna edo MIA errepikaria bezalako aldagai gogorretan murrizketarik ikusi gabe. Hala ere, kontuan izan behar da entsegu kliniko hauek GKKN aldagai konposatuan desberdintasunak aurkitzeko diseinatu direla eta, beraz, hilkortasuna eta MIA errepikaria bezalako aldagaiak aztertzeko duten potentzia txikiegia dela.

Bestalde, iskemiaren ondorioz birbaskularizazioa errepikatu beharra kontu handiz interpretatu beharreko datua da, klinikoki garrantzitsua izan arren alboratuta egon daitekeen aldagaia baita. Izan ere, medikuek zein pazienteek tratatu gabeko beste lesio esanguratsuen berri izateak IRA-PCI taldean birbaskularizazio-tasa altuagoak egotea eragin dezake, bereziki iskemia objektiboaz gain subjektiboa ere aintzat hartzen denean birbaskularizazioa egiteko (Politi, CVLPRIT, DANAMI- 3-PRIMULTI eta COMPARE-ACUTE entsegu klinikoetan gertatzen den bezalaxe). Hori kontuan izanik, PRAMI ikerketan iskemia objektiboki frogatzea eskatu da. Entsegu kliniko horretan birbaskularizazio-beharra eta angina errefraktarioa gutxitzeaz gain, MIA errepikaria ere gutxitu da birbaskularizazio osoko taldean. PRAMI ikerketaz gain, argitaratu berri den COMPLETE entsegu klinikoak, hilkortasun kardiobaskularra eta MIA aldagai konposatuan birbaskularizazioa osatzearen aldeko datuak erakutsi ditu, bereziki MIA gutxitzearen bitartez. Hala, aurreko entsegu klinikoetan emaitza esanguratsuak ez lortzea potentzia estatistiko txikiegia izatearen ondorioa izan daiteke.

\subsection{Argitzear dauden puntuak}

\subsubsection{S-PCl estrategia hautatuz gero, zein da momenturik egokiena?}

Etapakako birbaskularizazioa hautatuz gero, ez dago argi zein den momenturik egokiena birbaskularizazioa egiteko. Politi entsegu klinikoan birbaskularizazioa errepikatzea behar izan duten pazienteen \% 86k (6/7) programaturiko AKTParen aurretik behar izanak $(56,8 \pm 12,9$ egunera) eta CVLPRIT entsegu klinikoan ikusi den GKKN kurben banaketa goiztiarrak alta ondorengo etapakako birbaskularizazioa ospitale barnekoa bezain eraginkorra izango ez dela iradoki dezakete. 2019. urteko abenduan argitaratu berri den COMPLETE entsegu klinikoaren azpiikerketa batek, aldiz, ez du desberdintasunik aurkitu lehenengo 45 egunetan edo 45 egun igaro ondoren eginiko birbaskularizazio osoaren artean (35).

Beraz, dagoen ebidentzia oso urria da, entsegu kliniko desberdinetan etapakako birbaskularizazioa egiteko denbora-tarte desberdinak erabili dira eta, beraz, ezin da ondorio sendorik atera.

\subsubsection{Nola erabaki zein arteria ez errudun tratatu?}

Arteria ez erruduna baloratzeko modu desberdinak daude. Ikerketa gehienetan buxaduraren larritasuna angiografiaz ikusitako estenosi-diametroaren arabera ezarri da (ikuspuntu anatomikoa), arteria koronario nagusietan \% 70eko eta enborrean \%50eko buxadurak esanguratsutzat hartuz. Hala ere, PRAMI entsegu klinikoan muga \%50ean jarri da, lesioak ez dira iskemiaren arabera ebaluatu eta gainera inflamazio-erantzun sistemikoaren eta basoespasmoaren ondorioz lesioen larritasuna gainestimatua egon daiteke, MV-PCI taldean gaintratamendu bat eraginez.

PRAMI eta CVIPRIT bezalako entsegu kliniko handietan arteria ez errudunen larritasuna irudi angiografikoaren baitan ezarri den arren, maiz irudi angiografikoa eta lesioak duen eragin hemodinamikoa ez datoz bat (ikusiz eginiko ebaluazioa subjektiboa da eta esangura fisiologikoarekin korrelazio eskasa du).

Arteria ez errudunaren ikusizko balorazioaren mugak kontuan izanik, DANAMI-3-PRIMULTI ikerketan angiografiaren aldetik esanguratsuak diruditen lesioetan FFR erabili da lesioen eragin 
hemodinamikoa ezartzeko (ikuspuntu funtzionala). Ikerketa horretan, aipatu dugunez, S-PCl adarrera aleatorizatutako pazienteen \% 31n arteria ez erruduneko lesioa ez da hemodinamikaren aldetik esanguratsua izan. Antzeko zerbait gertatzen da COMPARE-ACUTE entsegu klinikoan. Bertan, STIMIAren testuinguruan angiografiaz ikusiz esanguratsutzat harturiko arteria ez errudunetatik (>\% 50 buxadura) \%57an FFRa negatiboa izan da $(>0,80)$, hau da, lesio ugarik ez dute esangura hemodinamikorik izan.

Hala ere, sindrome koronario akutu baten testuinguruan FFR ez dago balidatua arteria erruduna baloratzeko (buxadura mikrobaskularrak basodilatazio farmakologikoaren erantzuna gutxitzea eragin dezake, balio faltsu negatiboak emanez), lehenengo egunetan arteria ez errudunaren balorazioan duen papera zehazteke egonik (36).

Baina, arteria ez errudunak egoera kroniko gisa edo lesio koronario ezegonkor gisa ulertzen ditugu? STIMIA pairatu duten pazienteen arteria ez errudunen eta angina egonkorra duten pazienteen plaken konposizioa desberdinak direla dirudi eta horrek arteria ez errudunen MIArako aurrera egitean paper garrantzitsua izan dezake (ikuspuntu histologikoa). Beraz, ikuspuntu anatomikoa eta funtzionala, plaken osaera kontuan hartu gabe, erabaki hau hartzeko orduan motz geratu daitezkeela dirudi. Hala ere, gaur egun ez dago plaken konposizioa modu azkar, merke eta fidagarri batean identifikatzen duen metodorik eta, beraz, momentuz arteria ez errudunen balorazio histologikoa ezin da praktika klinikora eraman.

\subsubsection{Birbaskularizazio osoa, errutinaz paziente guztiei?}

Argi dago arteria guztiak irekita edukitzeak segurtasuna ematen digula, baina ezin dugu ahaztu birbaskularizazioa osatzeak ere bere konplikazioak dituela eta betiere pazienteak bere gain hartzen dituen arriskuen eta abantaila potentzialen artean erlazio egoki bat bermatu behar dugula. Horretarako birbaskularizazio osoaz baliatu daitezkeen "arrisku altuko pazienteak" identifikatu beharko genituzke: gure populazioan STIMIA baten testuinguruan arteria erruduna soilik ireki zaien pazienteen artean, zenbat arteria ez errudunek egin dute aurrera MIA bat emateraino? Aurrera egite hori jasan duten pazienteetan ezaugarri komunen bat identifikatu daiteke?

PRAGUE-13 entsegu klinikoan arrisku baxuko pazienteak aztertu dira; paziente horietan jarraipenean zehar oso arteria ez errudun gutxi konplikatu dira eta hala, ez da birbaskularizazio osoaren aldeko abantailarik ikusi. Entsegu kliniko honetan STIMIAren aurreko hilabetean angina (>2 CCS) jasan duten pazienteak alde batera utzi dira. Baztertze-irizpide horrek interes berezia dauka, aurretik angina izan duten pazienteak baztertuz potentzialki arrisku altukoa izan daitekeen talde bat alde batera uzten baita.

Lemeslek (37) eginiko ikerketan, 3 urteko jarraipenaren ondoren, soilik pazienteen \% 10ek behar izan du arteria ez errudunaren birbaskularizazioa. DM, gaixotasun baskular periferikoa eta bihotzeko bypass-a izatea arrisku-faktore gisa identifikatu dira, eta, beraz, paziente horiek neurri prebentibo oldarkorragoaz baliatu daitezke.

Dena dela, erabaki egoki bat hartu ahal izateko, pazienteen ezaugarri klinikoak kontuan hartzeaz gain, prozeduraren konplexutasuna, lesioaren esangura funtzionala (iskemia delako tratatu behar duguna) eta erasandako arteria (arriskuan dagoen miokardio kopuru desberdina) ere aintzat hartu behar dira. 


\section{Ondorioa}

Azken urteetan argitaratzen ari diren entsegu kliniko desberdinek, arteria ez errudunen birbaskularizazioa segurua dela iradokitzeaz gain, birbaskularizazio osoaren aldeko datuak agerian utzi dituzte, bereziki birbaskularizazio elektiboa eta miokardioko infartu akutua gutxitzearen eskutik.

Hala ere, arteria ez errudunen birbaskularizazioa egitea mesedegarria izan daitekeen arren, tratamendu egokienaren erabakia pertsonalizatu egin behar da, pazientearen ezaugarri klinikoak, angiografikoak, arriskuan dagoen miokardio kopurua eta prozeduraren konplexutasuna aintzat hartuz.

\section{Bibliografia}

1. Sorajja P, Gersh BJ, Cox DA, McLaughlin MG, Zimetbaum P, Costantini C, Stuckey T, Tcheng JE, Mehran R, Lansky AJ, Grines CL, Stone GW. Impact of multivessel disease on reperfusion success and clinical outcomes in patients undergoing primary percutaneous coronary intervention for acute myocardial infarction. Eur Heart J. 2007 Jul;28(14):1709-16.

2. Widimsky P, Holmes DR Jr. How to treat patients with ST-elevation acute myocardial infarction and multi-vessel disease? Eur Heart J. 2011 Feb;32(4):396-403. doi: 10.1093/eurheartj/ehq410.

3. Levine GN, Bates ER, Blankenship JC, Bailey SR, Bittl JA, Cercek B, Chambers CE, Ellis SG, Guyton RA, Hollenberg SM, Khot UN, Lange RA, Mauri L, Mehran R, Moussa ID, Mukherjee D, Ting HH, O'Gara PT, Kushner FG, Ascheim DD, Brindis RG, Casey DE Jr, Chung MK, de Lemos JA, Diercks DB, Fang JC, Franklin BA, Granger CB, Krumholz HM, Linderbaum JA, Morrow DA, Newby LK, Ornato JP, Ou N, Radford MJ, Tamis-Holland JE, Tommaso CL, Tracy CM, Woo YJ, Zhao DX. 2015 ACC/AHA/SCAI Focused Update on Primary Percutaneous Coronary Intervention for Patients With ST-Elevation Myocardial Infarction: An Update of the 2011 ACCF/AHA/SCAI Guideline for Percutaneous Coronary Intervention and the 2013 ACCF/AHA Guideline for the Management of ST-Elevation Myocardial Infarction: A Report of the American College of Cardiology/American Heart Association Task Force on Clinical Practice Guidelines and the Society for Cardiovascular Angiography and Interventions. Circulation. 2016 Mar 15;133(11):1135-47. doi: 10.1161/CIR.0000000000000336.

4. Ibanez B, James S, Agewall S, Antunes MJ, Bucciarelli-Ducci C, Bueno H, Caforio ALP, Crea F, Goudevenos JA, Halvorsen S, Hindricks G, Kastrati A, Lenzen MJ, Prescott E, Roffi M, Valgimigli M, Varenhorst C, Vranckx P, Widimský P; ESC Scientific Document Group. 2017 ESC Guidelines for the management of acute myocardial infarction in patients presenting with ST-segment elevation: The Task Force for the management of acute myocardial infarction in patients presenting with ST-segment elevation of the European Society of Cardiology (ESC). Eur Heart J. 2018 Jan 7;39(2):119-177. doi: 10.1093/eurheartj/ehx393.

5. Task Force on the management of ST-segment elevation acute myocardial infarction of the European Society of Cardiology (ESC), Steg PG, James SK, Atar D, Badano LP, Blömstrom-Lundqvist C, Borger MA, Di Mario C, Dickstein K, Ducrocq G, Fernandez-Aviles F, Gershlick AH, Giannuzzi P, Halvorsen S, Huber $K$, Juni $P$, Kastrati A, Knuuti J, Lenzen MJ, Mahaffey KW, Valgimigli M, van 't Hof A, Widimsky $P$, Zahger D. ESC Guidelines for the management of acute myocardial infarction in patients presenting with STsegment elevation. Eur Heart J. 2012 Oct;33(20):2569-619. doi: 10.1093/eurheartj/ehs215

6. Neumann FJ, Sousa-Uva M, Ahlsson A, Alfonso F, Banning AP, Benedetto U, Byrne RA, Collet JP, Falk V, Head SJ, Jüni P, Kastrati A, Koller A, Kristensen SD, Niebauer J, Richter DJ, Seferovic PM, Sibbing D, Stefanini GG, Windecker S, Yadav R, Zembala MO; ESC Scientific Document Group . 2018 ESC/EACTS Guidelines on myocardial revascularization. Eur Heart J. 2019 Jan 7;40(2):87-165. doi:10.1093/eurheartj/ehy394

7. O'Gara PT, Kushner FG, Ascheim DD, Casey DE Jr, Chung MK, de Lemos JA, Ettinger SM, Fang JC, Fesmire FM, Franklin BA, Granger CB, Krumholz HM, Linderbaum JA, Morrow DA, Newby LK, Ornato JP, Ou N, Radford MJ, Tamis-Holland JE, Tommaso CL, Tracy CM, Woo YJ, Zhao DX, Anderson JL, Jacobs AK, Halperin JL, Albert NM, Brindis RG, Creager MA, DeMets D, Guyton RA, Hochman JS, Kovacs RJ, Kushner FG, Ohman EM, Stevenson WG, Yancy CW; American College of Cardiology Foundation/American Heart Association Task Force on Practice Guidelines. 2013 ACCF/AHA guideline for the management of ST-elevation myocardial infarction: a report of the American College of 
Cardiology Foundation/American Heart Association Task Force on Practice Guidelines. Circulation. 2013 Jan 29;127(4):e362-425. doi: 10.1161/CIR.0b013e3182742cf6

8. Jeger R, Jaguszewski M, Nallamothu BN, Lüscher TF, Urban P, Pedrazzini GB, Erne P, Radovanovic D; AMIS Plus Investigators. Acute multivessel revascularization improves 1-year outcome in ST-elevation myocardial infarction: a nationwide study cohort from the AMIS Plus registry. Int J Cardiol. 2014 Mar 1;172(1):76-81. doi: 10.1016/j.ijcard.2013.12.083

9. Varani E, Balducelli M, Aquilina M, Vecchi G, Hussien MN, Frassineti V, Maresta A. Single or multivessel percutaneous coronary intervention in ST-elevation myocardial infarction patients. Catheter Cardiovasc Interv. 2008 Dec 1;72(7):927-33. doi: 10.1002/ccd.21722

10. Hannan EL, Samadashvili Z, Walford G, Holmes DR Jr, Jacobs AK, Stamato NJ, Venditti FJ, Sharma S, King SB 3rd. Culprit vessel percutaneous coronary intervention versus multivessel and staged percutaneous coronary intervention for ST-segment elevation myocardial infarction patients with multivessel disease. JACC Cardiovasc Interv. 2010 Jan;3(1):22-31. doi: 10.1016/j.jcin.2009.10.017

11. Toma M, Buller CE, Westerhout CM, Fu Y, O'Neill WW, Holmes DR Jr, Hamm CW, Granger CB, Armstrong PW; APEX-AMI Investigators. Non-culprit coronary artery percutaneous coronary intervention during acute ST-segment elevation myocardial infarction: insights from the APEX-AMI trial. Eur Heart J. 2010 Jul;31(14):1701-7. doi: 10.1093/eurheartj/ehq129

12. Iqbal MB, Ilsley $C$, Kabir $T$, Smith $R$, Lane $R$, Mason $M$, Clifford $P$, Crake $T$, Firoozi $S$, Kalra $S$, Knight $C$, Lim P, Malik IS, Mathur A, Meier P, Rakhit RD, Redwood S, Whitbread M, Bromage D, Rathod K, MacCarthy P, Dalby M; London Heart Attack Centre (HAC) Group Investigators. Culprit vessel versus multivessel intervention at the time of primary percutaneous coronary intervention in patients with ST-segment-elevation myocardial infarction and multivessel disease: real-world analysis of 3984 patients in London. Circ Cardiovasc Qual Outcomes. 2014 Nov;7(6):936-43. doi: 10.1161/CIRCOUTCOMES.114.001194

13. Bauer T, Zeymer U, Hochadel M, Möllmann H, Weidinger F, Zahn R, Nef HM, Hamm CW, Marco J, Gitt AK. Prima-vista multi-vessel percutaneous coronary intervention in haemodynamically stable patients with acute coronary syndromes: analysis of over 4.400 patients in the EHS-PCl registry. Int J Cardiol. 2013 Jul 1;166(3):596-600. doi: 10.1016/j.ijcard.2011.11.024

14. Cavender MA, Milford-Beland S, Roe MT, Peterson ED, Weintraub WS, Rao SV. Prevalence, predictors, and in-hospital outcomes of non-infarct artery intervention during primary percutaneous coronary intervention for ST-segment elevation myocardial infarction (from the National Cardiovascular Data Registry). Am J Cardiol. 2009 Aug 15;104(4):507-13. doi: 10.1016/j.amjcard.2009.04.016

15. Jaguszewski M, Radovanovic D, Nallamothu BK, Lüscher TF, Urban P, Eberli FR, Bertel O, Pedrazzini GB, Windecker S, Jeger R, Erne P; AMIS Plus Investigators. Multivessel versus culprit vessel percutaneous coronary intervention in ST-elevation myocardial infarction: is more worse? Eurolntervention. 2013 Dec;9(8):909-15. doi: 10.4244/EIJV9I8A153

16. Santos AR, Piçarra BC, Celeiro M, Bento Â, Aguiar J; investigadores do Registo Nacional de Síndromes Coronárias Agudas. Multivessel approach in ST-elevation myocardial infarction: impact on in-hospital morbidity and mortality. Rev Port Cardiol. 2014 Feb;33(2):67-73. doi: 10.1016/j.repc.2013.07.015

17. Di Mario C, Mara S, Flavio A, Imad S, Antonio M, Anna P, Emanuela P, Stefano DS, Angelo R, Stefania C, Anna F, Carmelo C, Antonio C, Monzini N, Bonardi MA. Single vs multivessel treatment during primary angioplasty: results of the multicentre randomised HEpacoat for cuLPrit or multivessel stenting for Acute Myocardial Infarction (HELP AMI) Study. Int J Cardiovasc Intervent. 2004;6(3-4):128-33

18. Ochala A, Smolka GA, Wojakowski W, Dudek D, Dziewierz A, Krolikowski Z, Gasior Z, Tendera M. The function of the left ventricle after complete multivessel one-stage percutaneous coronary intervention in patients with acute myocardial infarction. J Invasive Cardiol. 2004 Dec;16(12):699-702

19. Dambrink JH, Debrauwere JP, van 't Hof AW, Ottervanger JP, Gosselink AT, Hoorntje JC, de Boer MJ, Suryapranata H. Non-culprit lesions detected during primary $\mathrm{PCl}$ : treat invasively or follow the guidelines? Eurolntervention. 2010 Apr;5(8):968-75. doi: 10.4244/. 
20. Hlinomaz O, Groch L, Polokova L, Lehar F, Vekov T, Petkov R, Stojnev M, Griva M, Sitar J, Rezek M, Novak M, Semenka J, Penkov N. Multivessel coronary disease diagnosed at the time of primary PCl for STEMI: complete revascularization versus conservative strategy. Prague-13 trial. Kardiol Rev Int Med. 2015;17(3):214-220

21. Kowalewski M, Schulze V, Berti S, Waksman R, Kubica J, Kołodziejczak M, Buffon A, Suryapranata $H$, Gurbel PA, Kelm M, Pawliszak W, Anisimowicz L, Navarese EP. Complete revascularisation in STelevation myocardial infarction and multivessel disease: meta-analysis of randomised controlled trials. Heart. 2015 Aug;101(16):1309-17. doi: 10.1136/heartjnl-2014-307293

22. Manari A, Varani E, Guastaroba $P$, Menozzi M, Valgimigli M, Menozzi A, Magnavacchi P, Franco N, Marzocchi A, Casella G. Long-term outcome in patients with ST segment elevation myocardial infarction and multivessel disease treated with culprit-only, immediate, or staged multivessel percutaneous revascularization strategies: Insights from the REAL registry. Catheter Cardiovasc Interv. 2014 Nov 15;84(6):912-22. doi: 10.1002/ccd.25374

23. Politi L, Sgura F, Rossi R, Monopoli D, Guerri E, Leuzzi C, Bursi F, Sangiorgi GM, Modena MG. A randomised trial of target-vessel versus multi-vessel revascularisation in ST-elevation myocardial infarction: major adverse cardiac events during long-term follow-up. Heart. 2010 May;96(9):662-7. doi:10.1136/hrt.2009.177162

24. Wald DS, Morris JK, Wald NJ, Chase AJ, Edwards RJ, Hughes LO, Berry C, Oldroyd KG; PRAMI Investigators. Randomized trial of preventive angioplasty in myocardial infarction. N Engl J Med. 2013 Sep 19;369(12):1115-23. doi:10.1056/NEJMoa1305520

25. Kelly DJ, McCann GP, Blackman D, Curzen NP, Dalby M, Greenwood JP, Fairbrother K, Shipley L, Kelion A, Heatherington S, Khan JN, Nazir S, Alahmar A, Flather M, Swanton H, Schofield P, Gunning M, Hall R, Gershlick AH. Complete Versus culprit-Lesion only PRimary PCI Trial (CVLPRIT): a multicentre trial testing management strategies when multivessel disease is detected at the time of primary PCI: rationale and design. Eurolntervention. 2013 Feb 22;8(10):1190-8. doi:10.4244/EIJV8I10A183

26. Gershlick AH, Khan JN, Kelly DJ, Greenwood JP, Sasikaran T, Curzen N, Blackman DJ, Dalby M, Fairbrother KL, Banya W, Wang D, Flather M, Hetherington SL, Kelion AD, Talwar S, Gunning M, Hall R, Swanton H, McCann GP. Randomized trial of complete versus lesion-only revascularization in patients undergoing primary percutaneous coronary intervention for STEMI and multivessel disease: the CvLPRIT trial. J Am Coll Cardiol. 2015 Mar 17;65(10):963-72. doi:10.1016/j.jacc.2014.12.038

27. Gershlick AH, Banning AS, Parker E, Wang D, Budgeon CA, Kelly DJ, Kane PO, Dalby M, Hetherington SL, McCann GP, Greenwood JP, Curzen N. Long-Term Follow-Up of Complete Versus Lesion-Only Revascularization in STEMI and Multivessel Disease: The CVLPRIT Trial. J Am Coll Cardiol. 2019 Dec 24;74(25):3083-3094. doi:10.1016/j.jacc.2019.10.033

28. Engstrøm T, Kelbæk H, Helqvist S, Høfsten DE, Kløvgaard L, Holmvang L, Jørgensen E, Pedersen F, Saunamäki K, Clemmensen P, De Backer O, Ravkilde J, Tilsted HH, Villadsen AB, Aarøe J, Jensen SE, Raungaard B, Køber L; DANAMI-3-PRIMULTI Investigators. Complete revascularisation versus treatment of the culprit lesion only in patients with ST-segment elevation myocardial infarction and multivessel disease (DANAMI-3-PRIMULTI): an open-label, randomised controlled trial. Lancet. 2015 Aug 15;386(9994):665-71

29. Smits PC, Abdel-Wahab M, Neumann FJ, Boxma-de Klerk BM, Lunde K, Schotborgh CE, Piroth Z, Horak D, Wlodarczak A, Ong PJ, Hambrecht R, Angerås O, Richardt G, Omerovic E; Compare-Acute Investigators. Fractional Flow Reserve-Guided Multivessel Angioplasty in Myocardial Infarction. N Engl J Med. 2017 Mar 30;376(13):1234-1244. doi: 10.1056/NEJMoa1701067

30. Mehta SR, Wood DA, Storey RF, Mehran R, Bainey KR, Nguyen H, Meeks B, Di Pasquale G, LópezSendón J, Faxon DP, Mauri L, Rao SV, Feldman L, Steg PG, Avezum Á, Sheth T, Pinilla-Echeverri N, Moreno R, Campo G, Wrigley B, Kedev S, Sutton A, Oliver R, Rodés-Cabau J, Stanković G, Welsh R, Lavi S, Cantor WJ, Wang J, Nakamya J, Bangdiwala SI, Cairns JA; COMPLETE Trial Steering Committee and Investigators. Complete Revascularization with Multivessel PCI for Myocardial Infarction. N Engl J Med. 2019 Oct 10;381(15):1411-1421. doi: 10.1056/NEJMoa1907775 
31. Kornowski R, Mehran R, Dangas G, Nikolsky E, Assali A, Claessen BE, Gersh BJ, Wong SC, Witzenbichler B, Guagliumi G, Dudek D, Fahy M, Lansky AJ, Stone GW; HORIZONS-AMI Trial Investigators. Prognostic impact of staged versus "one-time" multivessel percutaneous intervention in acute myocardial infarction: analysis from the HORIZONS-AMI (harmonizing outcomes with revascularization and stents in acute myocardial infarction) trial. J Am Coll Cardiol. 2011 Aug 9;58(7):704-11. doi: 10.1016/j.jacc.2011.02.071

32. Tarasov RS, Ganyukov VI, Protopopov AV, Barbarash OI, Barbarash LS. Six month results of randomized clinical trial: multivessel stenting versus staged revascularization for ST-elevation myocardial infarction patients with second generation drug eluting stents. Clin Med Res. 2014; 3:125-9.

33. Maamoun W, Elkhaeat N, Elarasy R. Safety and feasibility of complete simultaneous revascularization during primary PCI in patients with STEMI and multivessel disease. Egyptian Heart J. 2011;63:39-43.

34. McCann GP, Khan JN, Greenwood JP, Nazir S, Dalby M, Curzen N, Hetherington S, Kelly DJ, Blackman DJ, Ring A, Peebles C, Wong J, Sasikaran T, Flather M, Swanton H, Gershlick AH. Complete Versus Lesion-Only Primary PCl: The Randomized Cardiovascular MR CvLPRIT Substudy. J Am Coll Cardiol. 2015 Dec 22;66(24):2713-2724. doi: 10.1016/j.jacc.2015.09.099

35. Wood DA, Cairns JA, Wang J, Mehran R, Storey RF, Nguyen H, Meeks B, Kunadian V, Tanguay JF, Kim $\mathrm{HH}$, Cheema A, Deghani P, Natarajan MK, Jolly SS, Amerena J, Keltai M, James S, Hlinomaz O, Niemela K, AlHabib K, Lewis BS, Nguyen M, Sarma J, Dzavik V, Della Siega A, Mehta SR; COMPLETE Investigators. Timing of Staged Nonculprit Artery Revascularization in Patients With ST-Segment Elevation Myocardial Infarction: COMPLETE Trial. J Am Coll Cardiol. 2019 Dec 3;74(22):2713-2723. doi: 10.1016/j.jacc.2019.09.051

36. Berry C, Corcoran D, Hennigan B, Watkins S, Layland J, Oldroyd KG. Fractional flow reserve-guided management in stable coronary disease and acute myocardial infarction: recent developments. Eur Heart J. 2015 Dec 1;36(45):3155-64. doi:10.1093/eurheartj/ehv206

37. Lemesle G, de Labriolle A, Bonello L, Torguson R, Kaneshige K, Xue Z, Suddath WO, Satler LF, Kent KM, Lindsay J, Pichard AD, Waksman R. Incidence, predictors, and outcome of new, subsequent lesions treated with percutaneous coronary intervention in patients presenting with myocardial infarction. Am J Cardiol. 2009 May 1;103(9):1189-95. doi: 10.1016/j.amjcard.2009.01.029

\section{Eranskineko taulak}

Testuan zehar aipatu diren behaketa-ikerketa eta entsegu klinikoen oinarrizko ezaugarriak, emaitza nagusiak eta mugak zehaztasun handiagoz alderatzen dira hemen: www.osagaiz.eus/rt/suppFiles/292/0 